\title{
Research on Teaching Assistant System of Public Basic Courses in Colleges and Universities
}

\author{
Qi Li \\ Basic Teaching Department, Shandong Huayu University of Technology, Dezhou, Shandong, China 253034
}

Keywords: public basic course; J2EE technology; system design

\begin{abstract}
Teaching management is an important part of school education in colleges and universities. Especially the management of public basic course teaching assistant system is very difficult and complicated. It is difficult to preserve the teaching audio and video and the resources taught by teachers. The follow-up review and use of students is also very flawed. The teaching of public basic courses belongs to the daily important work of the school, so it is necessary to fully rely on network resources to integrate teaching resources into the computer, so that students can use these resources in class to improve students' learning efficiency. Therefore, it is required to study a set of teaching assistant for public foundation courses. Based on the actual situation, each user can use the relevant functions to apply the public basic course teaching assistant system according to the different authority, which is helpful for the teaching of public basic courses.
\end{abstract}

\section{Introduction}

Due to the continuous improvement of information infrastructure education equipment and facilities, many teaching assistant systems have relatively backward functions, which has great problems for the promotion of software. At present, many teaching management systems have introduced optimized solutions [6]. Although many schools use this similar system, due to the many requirements of the public basic course, the later work is more difficult, and its system has not played a very good role in the past education system.

In view of the fact that the current teaching assistant system cannot meet the actual needs, this paper starts from the actual research situation, plans and analyzes the network teaching aid course, and at the same time conducts the network course planning and analysis to build a complete teaching assistant system platform. The realization of this platform helps to strengthen the interrelationship between courses, realize the sharing operation of teaching data resources, and improve students' understanding of course knowledge. It can not only enhance communication and communication between courses, but also improve the quality of students' learning.

\section{Design of Teaching Assistant System for Public Basic Courses}

\subsection{Design of system function structure}

The modules of information release, document management, teaching resource management, auxiliary teaching management and system management are the main components of the assistant teaching of public basic courses. The ways and means of information release may include news, announcements, and intramural websites; relative document management can be divided into: document management, receipt management, and archive management; the entire teaching assistant structure is divided into online courses, online exams, and homework, collection and correction, etc.; system aspects can be divided into teacher and student information management, system settings, feedback system management. The functional structure of public basic course assistant teaching management system is shown in Figure 1. 


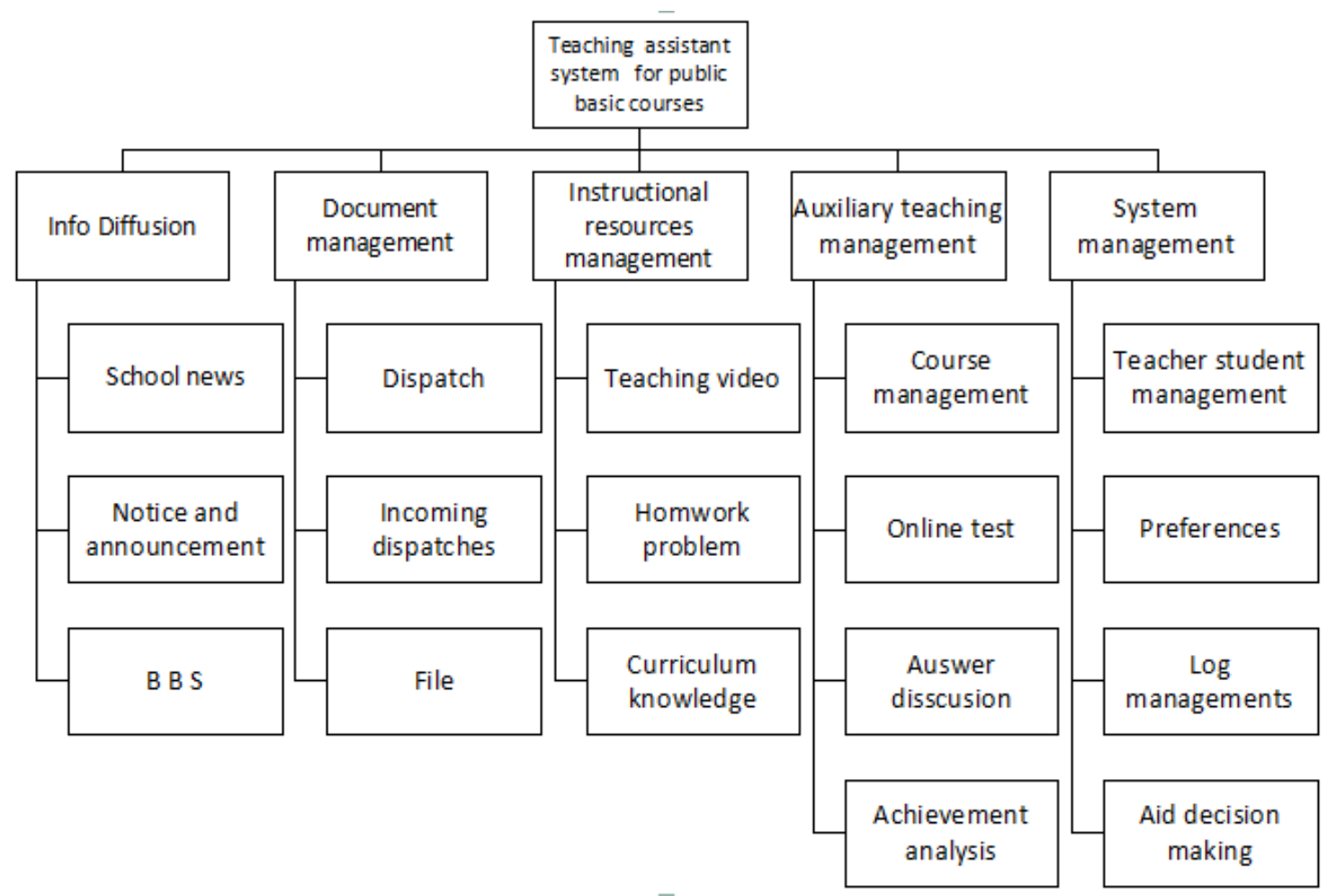

Figure 1 System function structure diagram

\subsection{Design of system}

\subsubsection{Design of information release management function}

This function is one of the functions commonly used by users. It needs to complete the function of information release. The release of news and announcement information can release daily information data to users. This management focuses on the processing and display operations of information, including the corresponding operation processing such as the release of information data, the editing of file data, and the deletion of information data. At the same time, this function also includes the setting of identification data and the information file, editing, verification of information, etc. Through the application of this function module, the security and sensitivity can be greatly improved, so different system administrators can complete different settings and processing.

\subsubsection{Design of document management function}

The document management function includes three modules: document management, receipt management, and archive management.

As for design of administrative document management, in the school, the administrative documents will be specially prepared by the staff. The specific operation process is: (1) the school needs special personnel to carry out the drafting and operation; (2) choose the appropriate template for the file processing operation; (3) After the manuscript operation is completed, the proposed selection is made, and then the corresponding information is filled in the document; (4) the text needs to be completed after the data is completed, and the user can also select the attachment upload operation; (5)According to the operation process, the relevant person in charge of the school needs to review and approve the document before it can be released. (6) The office staff re-improves the file, then types it, and then uploads and publishes it; (7) After the data is released, the file needs to be classified and saved.

\subsubsection{Design of teaching resource management function}

The teaching resources include resource files such as courseware data, exercise data, and teacher's lesson information data used by students. In addition, teachers can record corresponding instructional videos that are very valuable to students. Students can download and watch videos and 
learn from video files. (1) Management of teaching course video. Through this function, the user can complete the operation of adding and deleting video data, and use the database language to complete the corresponding operation. At the same time, the user can also browse the video files in the system and download relevant video files to learn. (2) Management and operation of courseware documents. The courseware file is a function used by the user. The teacher can upload the courseware file to the system server, and then the user can download and use it to the desktop, and download it from the database server during use. (3) Management operations of the homework function. When users use this function, they need to upload the completed content to the system, and then the teacher user can view the file data. (4) Management of course content. This is mainly the function of the teacher. The teacher user can manage and maintain the course data.

\subsubsection{Design of assistant teaching management function}

This function mainly includes communication between teachers and students, video data management functions, performance data management and question bank data management.

(1) Teaching course question bank management function module. In this function template, you can manage the test question bank information, test question editing, answer editing, and so on. In the process of classification management, it is mainly possible to add, modify and delete test information data, such as selection, fill in the blank, objective questions and so on. The management of the answer data includes the addition, modification and deletion of the answer information, and each answer must have corresponding test information.

(2) Online exam management module. The online exam module and functions include system automatic matching test papers and student online answering questions, system automatic scoring and other functional modules. Automatic matching of test papers: The system can automatically set the title and test paper according to the category and number of questions set by the teacher. After the verification, the questions can be extracted from the system database, so that the user can implement the network test after logging in to the system.

(3) Score management module. The score management section includes both student and teacher users who can use and participate. The teacher user can query and manage the student's grades, and can also calculate the student's test score distribution and help students print test scores and other operations.

(4) Courseware video and data release and download module. The courseware is mainly used by the teacher to upload the spatial data to the system server through the upload function, so that the student user can conveniently view the courseware data through the browser. Since the recognition function of the system requires that the format of the courseware data uploaded by the teacher must be in the word format or the pdf format, the operation of the student can expand the knowledge of the student and deepen the understanding and mastery of the teaching curriculum.

(5) Teacher and student exchange module. The whole system provides functional modules for teachers and students to communicate, which is more suitable for users to communicate through this platform. There are two forms: forum form and question and answer form.

\subsubsection{Design of System Management Function}

There should be an administrator setting function in the system setting function. The user must verify his identity when using the system, and then can operate in the system, store the contents of the data and information in the database, and retrieve the data information from the database when using it. But the development and design use J2EE technology development software, you must use the ADOQuery class, with this class to help the system to complete the operation, especially after using the database, you must use ADOQuery freely to release the database. Otherwise, the data read directly from the database may be cached next time.

\section{Conclusion}

Through the use of the public basic course teaching assistant system, it can be found that students will repeat the same problem in the learning process, and the consultation of the problem 
can greatly reduce the students' doubts, and at the same time, it will be more beneficial to teachers. A comprehensive understanding of the students is in order to find a more appropriate learning method for students themselves. On this basis, statistical analysis of these issues can also be carried out, so that teachers can more intuitively see problems, analyze problems and solve problems, and then summarize the teaching methods more suitable for students' learning. Recording can leave a deeper impression on teachers, so that they can more comprehensively analyze and solve problems that are often encountered in teaching, and find more intuitive and effective teaching methods. However, students can also find their own deficiencies through the input of system keywords, so that they can recognize the shortcomings of their public basic courses and solve them in time, thereby improving efficiency and mobilizing the enthusiasm and initiative of students.

\section{Acknowledgements}

This work was supported by the project of Humanities and Social Sciences Research Plan Project in Shandong Province in 2016 (Code: J16WB01) and "Twelfth Five-Year Plan" of Education Science Project in Shandong Province (Code; CBS15007).

\section{References}

[1] Li Guizhi, Wang Wei, Zhou Changsheng. Design and Implementation of VB Curriculum Practice Teaching Assistant System[J]. Education and Teaching Forum, 2016(17): 220-221.

[2] Ye Li, Li Feng. Design and Implementation of Laboratory Multimedia Teaching Assistant System[J]. Computer and Network, 2015(15): 54-56.

[3] Li Ruiqiang. Design and Implementation of Computer Teaching Assistant System Based on WeChat Public Platform[J]. Computer \& Telecommunications, 2016(6): 43-45.

[4] Tian Xiaohui. Design and Implementation of Teaching Assistant System in Colleges and Universities[J]. Information and Computer: Theoretical Edition, 2016(19): 95-97.

[5] Tu Yizhen, Zhou Hui. Design and Implementation of C Language Teaching Assistant System in Higher Vocational Colleges[J]. Digital World, 2016(12): 226-226.

[6] Cao Lian. Design and implementation of classroom teaching assistant system based on We Chat Huazhong University of Science and Technology, 2016.

[7] Zhai Pan, Meng Yunrui, Xiao Peng. Design and Implementation of Teaching Assistant System for College Teachers Based on Android[J]. Digital Communication World, 2016(6): 90-92. 